\title{
Creep Fracture Mechanisms and Maps in Aisi Type 316 Austenitic Stainless Steels from Distinct Origins
}

\author{
Sergio Neves Monteiro *; Luiz Paulo Mendonça Brandão ${ }^{a}$, Andersan dos Santos Paula ${ }^{a}$, Carlos \\ Nelson Elias ${ }^{a}$, Artur Camposo Pereira ${ }^{a}$, Foluke Salgado de Assis ${ }^{a}$, Luiz Henrique de Almeida ${ }^{b}$, \\ Leonardo Sales Araújo \\ aPrograma de Ciência dos Materiais, Instituto Militar de Engenharia - IME, Praça General Tibúrcio, \\ 80, Praia Vermelha, 22290-270, Urca, Rio de Janeiro, RJ, Brasil \\ ${ }^{b}$ Departamento de Engenharia Metalúrgica e de Materiais, Universidade Federal do Rio de Janeiro - \\ UFRJ, CP 68505, CEP 21945-970, Rio de Janeiro, RJ, Brasil
}

Received: January 01, 2017; Revised: November 03, 2017; Accepted: January 23, 2018

\begin{abstract}
Two distinct AISI type 316 stainless steels, of Brazilian and Swedish origins, were compared regarding their creep fracture mechanisms at 600,700 and $800^{\circ} \mathrm{C}$. The possible mechanisms associated with the creep fracture strength were identified by means of fracture maps proposed either by Ashby and collaborators or by Miller and Langdon. Experimental creep results were consistent with the general Ashby and collaborators map for face centered cubic alloys. By contrast, the two different 316 steel displayed significant differences in the model-based map of Miller and Langdon. In the present work, changes in the maps frontier are proposed as well as the introduction of a new field in the map related to grain boundary precipitation. These propositions allowed the Miller and Langdon map to be coherent with the experimental creep fracture results of both 316 stainless steels.
\end{abstract}

Keywords: Creep fracture, AISI 316 stainless steel, fracture mechanisms, fracture map.

\section{Introduction}

Structural applications of AISI type 316 austenitic stainless steel (316 steel for short) at high temperatures in nuclear reactors ${ }^{1-4}$, normally involve constant load conditions. Under such conditions, plastic strains are continuously being accumulated in the well-known creep process $^{5}$. Unless the steel components are replaced, the accumulation of strain with time accelerates towards the so-called stage III creep until fracture occurs. Creep fracture is the result of a rupture process involving mechanisms of nucleation, growth and interconnection of cavities and pores followed by crack formation and propagation ${ }^{6}$. These are the typical fracture mechanisms before final failure in ductile materials like the 316 steel subjected to long time high temperature conditions. In general, three basic types of damages may occur: high plasticity $\mathbf{p}$ dimples (microcavities); wedge $\mathbf{w}$ cavities, lenticular $\mathbf{r}$ cavities and pores. In short time creep, $\mathbf{p}$ dimples predominate in association with transgranular fracture. In long time creep, which is the usual situation for industrial applications, both $\mathbf{w}$ and $\mathbf{r}$ cavities predominate in association with intergranular fracture. Each of these initial processes of creep fracture in ductile alloys become the controlling mechanism depending on the stress, temperature and strain rate. They can be visualized in stress versus temperature maps. Ashby et al. ${ }^{7}$ proposed an experimental map, while Miller and Langdon ${ }^{8}$ proposed a model-based map for fracture. Both maps ${ }^{7,8}$ are limited in the validity to interpret creep fracture because of simplified hypothesis in their construction. Moreover, the degree of practical advantage in using a map by an industrial sector will depend on its ability to describe the correct time $\mathbf{t}_{\mathbf{f}}$ up to fracture. If one can predict the total time to fracture of a component operating under creep conditions, then it is possible to promote preventive maintenance with the purpose of replacing the component.

The experimental map of Ashby et al. ${ }^{7}$ was constructed from a large amount of data obtained in creep tests in which the dominant fracture mechanism is identified by optical (OM) and scanning electron (SEM) microscopies. The corresponding stress/temperature field is established for each mechanism. Boundaries between different fields are then estimated.

The model-based map of Miller and Langdon ${ }^{8}$ was constructed by considering the constitutive equations corresponding to the distinct creep fracture mechanisms. The field of a dominant mechanism, operating independently, is associated with the stress versus temperature locus, where $\mathbf{t}_{\mathrm{f}}$, is lower than those of other possible mechanisms. In principle, both maps could be applied to any material subjected to creep condition. Particularly, as aforementioned, 
there is a considerable industrial interest in predicting $\mathbf{t}_{\mathbf{r}}$ for 316 steel components operating at higher temperatures. However, stainless steels do not follow a simple development of creep damage as in pure metals 9 . In fact, since early works ${ }^{10,11}$, it has been established that this class of material presents a complex fracture behavior when subjected to high temperature creep conditions. Indeed, austenitic stainless steels are highly sensitive to thermo-mechanical processing history ${ }^{10}$. Moreover, they may suffer carbide precipitation and undergo phase transformations ${ }^{11-14}$. Among these, sigma phase transformation is considered one of the main reasons for the deterioration of stainless steels properties ${ }^{14}$. Indeed, as an intermetallic phase, $(\mathrm{FeNi})_{\mathrm{x}}(\mathrm{CrMo})_{\mathrm{y}}$, sigma may occur in 316 steel causing loss in toughness and matrix depletion in $\mathrm{Cr}$, $\mathrm{Ni}$ and $\mathrm{Mo}^{15}$. In addition, it has been recently found ${ }^{16}$ that, from $200^{\circ} \mathrm{C}$ up to $600^{\circ} \mathrm{C}$, dynamic strain aging (DSA) affects the mechanical properties and consequently might influence the high temperature creep fracture. These facts were not taken into account in the construction of a modelbased map by Miller and Langdon ${ }^{8}$.

Based on these assertions, the objective of the present work was to investigate the creep fracture mechanisms, experimentally observed in two 316 steels of different origins tested at 600,700 and $800^{\circ} \mathrm{C}$. The study is aimed to the comparison between their differences in creep fracture and the implications in terms of $\mathbf{t}_{\mathbf{f}}$ prediction by the distinct maps. The reason to investigate distinct steels of the same 316 type is due do different creep rupture results found in two creep tested 316 weld metals by Senior ${ }^{12}$.

\section{Experimental Procedure}

Two distinct, but of the same AISI type 316 austenitic stainless steels (316 steels for short) were investigated. One Brazilian (SS1), supplied by Villares and the other Swedish (SS2), supplied by Sandvik. The chemical composition and average grain size of these 316 steels are listed in Table 1 .

Both steels were received as hot-rolled bars with 100 $\mathrm{mm}$ in diameter. They were solution treated at $1100^{\circ} \mathrm{C}$ for complete annealed microstructure displaying final grain size around $80 \mu \mathrm{m}$. Round specimens for creep test were machined to $6 \mathrm{~mm}$ in gage diameter and $28 \mathrm{~mm}$ in gage length as per ASTM standard ${ }^{17}$. Creep tests were conducted in a WPM, Germany, equipment inside a furnace with open air chamber. Constant load conditions, corresponding to initial stress in the range of 40 to $350 \mathrm{MPa}$ were imposed to specimens tested at 600,700 and $800^{\circ} \mathrm{C}$ until fracture. Metallographic samples were taken from the fracture tips of creep tested specimens and observed by optical microscopy (OM) after polishing until diamond paste and etched with Vilella's reagent. Scanning electron microscopy (SEM) in a model Quanta FEG 250 FEI microscope was used to analyze the fracture tips of the specimens.

\section{Results and Discussion}

Typical strain vs. time creep curves for both 316 steels are shown in Fig. 1. It should be noted the relatively similar creep behavior of both steels at 600 and $700^{\circ} \mathrm{C}$ up to rupture times less than 2,000 hours. Similarity is also observed for shorter $(<500 \mathrm{~h})$ time creep at $800^{\circ} \mathrm{C}$. However, for longer time $(\sim 1,000 \mathrm{~h}) \mathrm{SS} 1$ steel has a much lower rupture strain $(\sim 20 \%)$ than SS2 (65\%). Parametric interpretation of the strain vs. time curves for both 316 steels revealed a power law relationship between the stress and the steady-state creeporate $^{5}$. The power exponent $\mathbf{n}$ was found to change from 5 to 9 with increasing temperature from 600 to $800^{\circ} \mathrm{C}$, in association with transgranular fracture. However, for long time SS1 creep tested at $800^{\circ} \mathrm{C}$, Fig. 1, which displays intergranular fracture, the value of $\mathbf{n}$ was around 3.

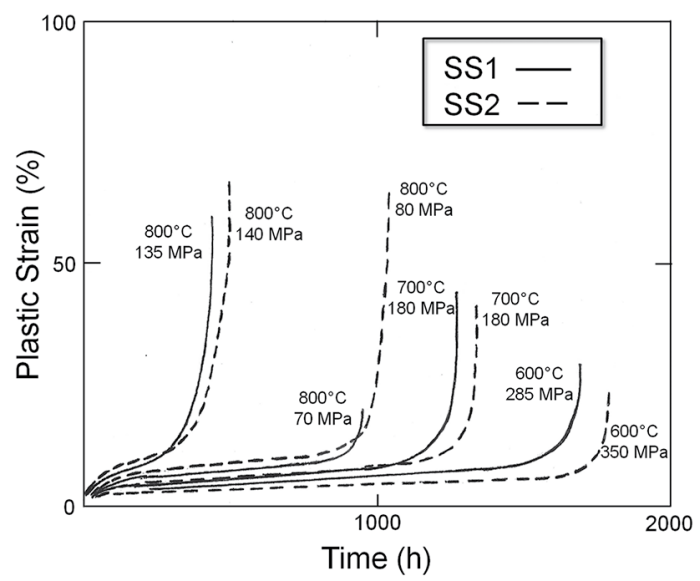

Figure 1. Typical strain vs. time curves for SS1 and SS2 type 316 steels creep tested at 600,700 and $800^{\circ} \mathrm{C}$.

In order to associate the creep fracture mechanisms with related fields in an experimental map, it was necessary to identify the corresponding fracture characteristics. According to Ashby et al. ${ }^{7}$ the fracture mechanisms of several alloys might be identified by the criteria of: morphological aspects of failure; existence of cavities at the grain boundary; and level of ductility. Following these criteria, the creep fracture of all tested specimens for both steels at $600^{\circ} \mathrm{C}$ displayed the same general features, shown in Fig. 2: transgranular failure, Fig. 2a; existence of wedge cavities at the grain boundaries, Fig. 2b; and level of moderate ductility given by $25-50 \%$ of reduction in area (RA) ${ }^{18}$.

At $700^{\circ} \mathrm{C}$, as illustrated $n$ Fig. 3, creep fracture of both 316 steels presented the same characteristics of: transgranular morphology; dimples (micro-cavities); and high ductility, RA $=50-70 \%{ }^{14}$. By contrast, creep tests performed at $800^{\circ} \mathrm{C}$ displayed different features for each steel. The Swedish SS2 steel displayed at $800^{\circ} \mathrm{C}$ creep fracture similar to those of both steels at $700^{\circ} \mathrm{C}$, Fig. 3, as well as for short time creep 
Table 1. Chemical composition (wt $\%$ ) and average grain size of the investigated 316 steels.

\begin{tabular}{|c|c|c|c|c|c|c|c|c|c|}
\hline AISI 316 & $\mathrm{C}$ & $\mathrm{Cr}$ & $\mathrm{Ni}$ & Mo & $\mathrm{Mn}$ & $\mathrm{Si}$ & $\mathrm{P}$ & $\mathrm{S}$ & $\begin{array}{l}\text { Grain Size } \\
\qquad(\mu \mathrm{m})\end{array}$ \\
\hline SS1 & 0.05 & 17.7 & 12.2 & 2.07 & 0.73 & 0.40 & 0.035 & 0.018 & 80 \\
\hline $\mathrm{SS} 2$ & 0.07 & 18.3 & 12.5 & 2.55 & 1.72 & 0.50 & 0.026 & 0.014 & 84 \\
\hline Standard & $0.08(\max )$ & $16-18$ & $10-14$ & $2-3$ & $2(\max )$ & $1(\max )$ & $0.045(\max )$ & $0.03(\max )$ & NS \\
\hline
\end{tabular}

NS: not specified.

of SS1 at $800^{\circ} \mathrm{C}$.In the case of the Brazilian SS1 steel, two situations have to be considered. For all short time creep, conducted at relatively higher stresses, the fracture depicted the following aspects, also found at $700^{\circ} \mathrm{C}$ : transgranular fracture surface covered with dimples; highly deformed grains with very small amount of grain boundary cavities; and high ductility, RA $=50-75 \%{ }^{18}$.

As shown in Fig. 4, for long time creep test at $800^{\circ} \mathrm{C}$, under relatively lower stresses, the following characteristics were uniquely observed in the Brazilian SS1 steel: intergranular fracture, Fig. 4a; profuse precipitation at the grain boundaries with formation of crack-like cavities, Fig. 4b; and moderate ductility, with RA $\sim 20 \%$.

The dark and elongated aspect of precipitates at the middle of Fig. $4 \mathrm{~b}$ resembles those of sigma phase reported by Villanueva et al. ${ }^{15}$ in 316 steel. However, the relatively short rupture time $(\sim 1,000 \mathrm{~h})$ might cast doubt of sigma phase formation, since it generally demands thousands hours in austenitic steels ${ }^{15}$.

In fact, the literature indicates sigma phase formation in 316 steels after long-term exposure between 600 and $1,000^{\circ} \mathrm{C}$, although its predictability is difficult ${ }^{12,14}$. On the other hand, sigma phase transformation could be accelerated in the presence of reasonable amounts of $\mathrm{Cr}, \mathrm{Si}$ and Mo. Using the classic Woodyatt's prediction ${ }^{19}$ :

$\mathrm{N}_{\mathrm{v}}=0.66 \mathrm{Ni}+1.71 \mathrm{Co}+2.66 \mathrm{Fe}+4.66(\mathrm{Cr}, \mathrm{Mo}, \mathrm{W})+$

$\% .66 \mathrm{~V}+6.66 \mathrm{Zr}+10.66 \mathrm{Nb}$

one finds for SS1 $\mathrm{N}_{\mathrm{v}}=2.78$, which is above the transformation threshold value of 2.52. Additionally, thermodynamic evaluation was performed via Thermo-Calc ${ }^{\circledR}$ software (version 2017a) with TCFE database. Figure 5 shows a step cooling phase mass fraction vs. temperature diagram from Thermo-Calc for the SS1 steel. From this diagram, one could infer that sigma phase is stable, in minor amounts, at $800^{\circ} \mathrm{C}$ in SS1 steel.

Based on the aspect of the precipitates in Fig. $4 \mathrm{~b}$ and the diagram in Fig. 5, one might consider the possibility of sigma phase transformation. In this case, comparatively reduction in both, rupture strain, Fig. 1, and value of RA $(\sim 20 \%)$ for relatively longer time creep of SS1 at $800^{\circ} \mathrm{C}$, could have been influenced by grain boundary precipitation of sigma phase.

A diagram that summarizes these creep fracture characteristics for both 316 steels is schematically presented in Fig. 6. The reasons for the marked different behavior of $\mathrm{SS} 1$ and SS2 at $800^{\circ} \mathrm{C}$ will be further discussed together with the inconsistency observed between these results and those presented in the model-based fracture map ${ }^{8}$.

The predicted fracture characteristics from the Miller and Langdon ${ }^{8}$ model-based maps for two grain sizes in Fig. 7 do not correspond to the experimental results shown in Fig. 1 to 4 . In principle, this discrepancy between predicted and experimentally obtained results could be justified in terms of the uncertainties in the values chosen ${ }^{5}$ for the parameters of the constitutive equations. However a more fundamental contradiction exists between the model-based maps for type 316 steel $^{8}$ and the experimental results. The Miller and Langdon ${ }^{8}$ maps in Fig. 7 do not allow for a possible transition, experimentally indicated in Fig. 6, from high
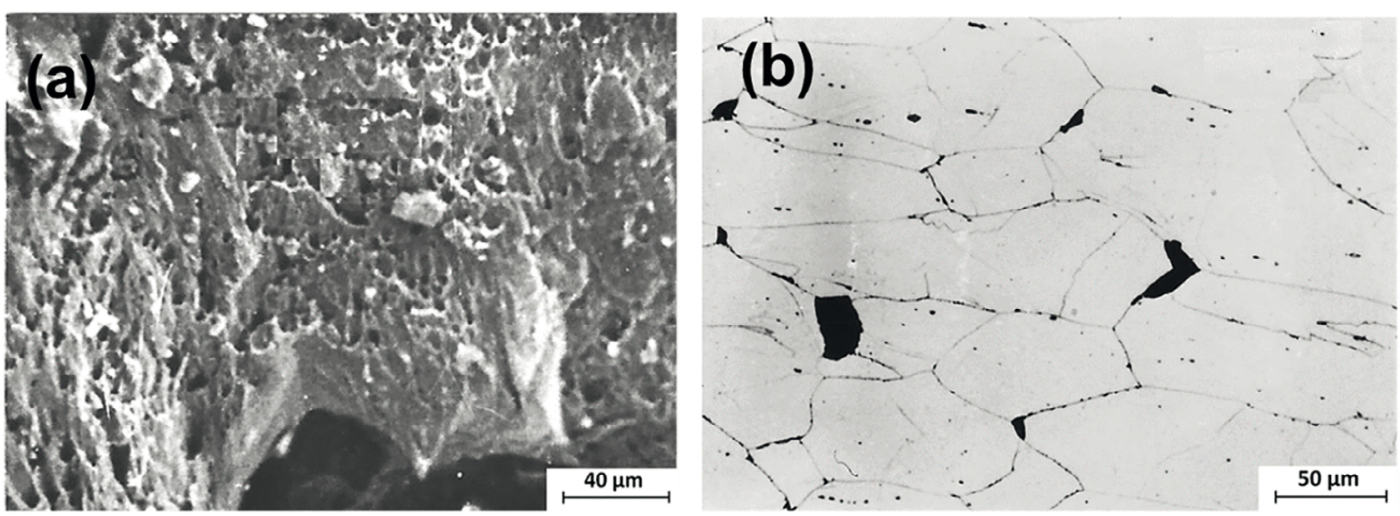

Figure 2. Ruptured tip of investigated 316 steels at $600^{\circ} \mathrm{C}$ : (a) SEM fractograph of SS1 steel with RA $=31 \%$ under stress of 300 $\mathrm{MPa}$ and (b) OM of SS2 steel with RA $=25 \%$ under $265 \mathrm{MPa}$. 

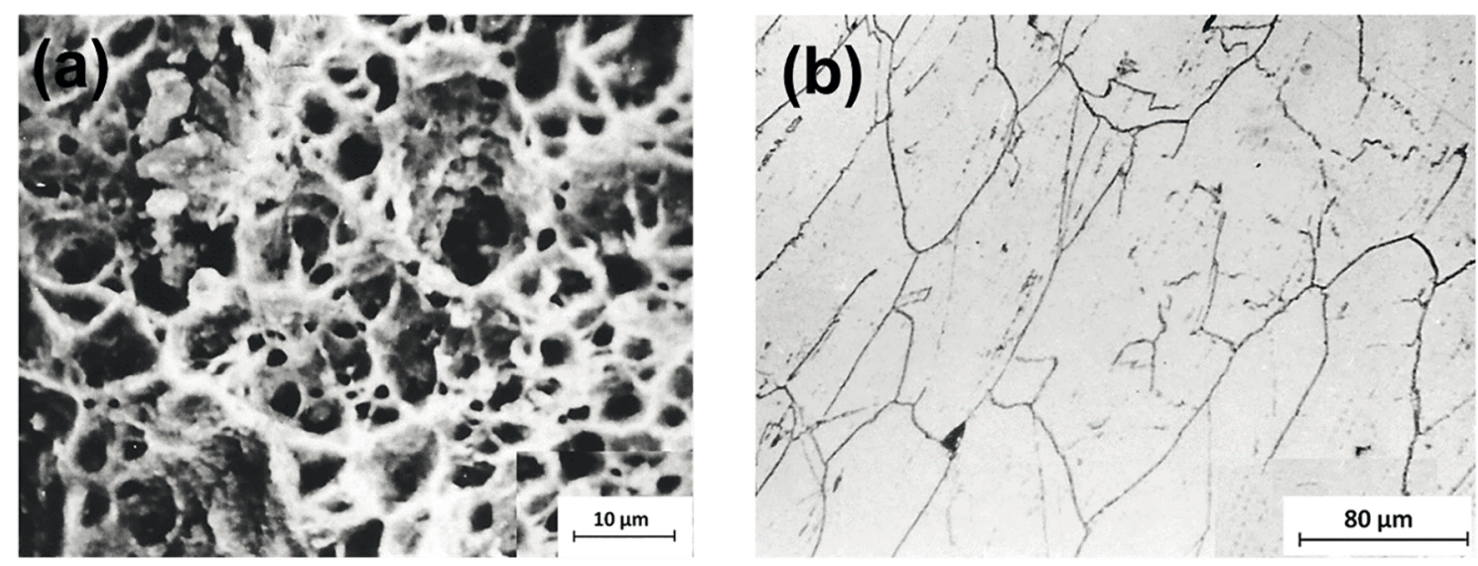

Figure 3. Ruptured tip of investigated 316 steels at $700^{\circ} \mathrm{C}$ : (a) SEM fractograph of SS1 steel with RA $=75 \%$ under stress of $180 \mathrm{MPa}$ and (b) OM of SS2 steel with RA $=60 \%$ under $190 \mathrm{MPa}$.
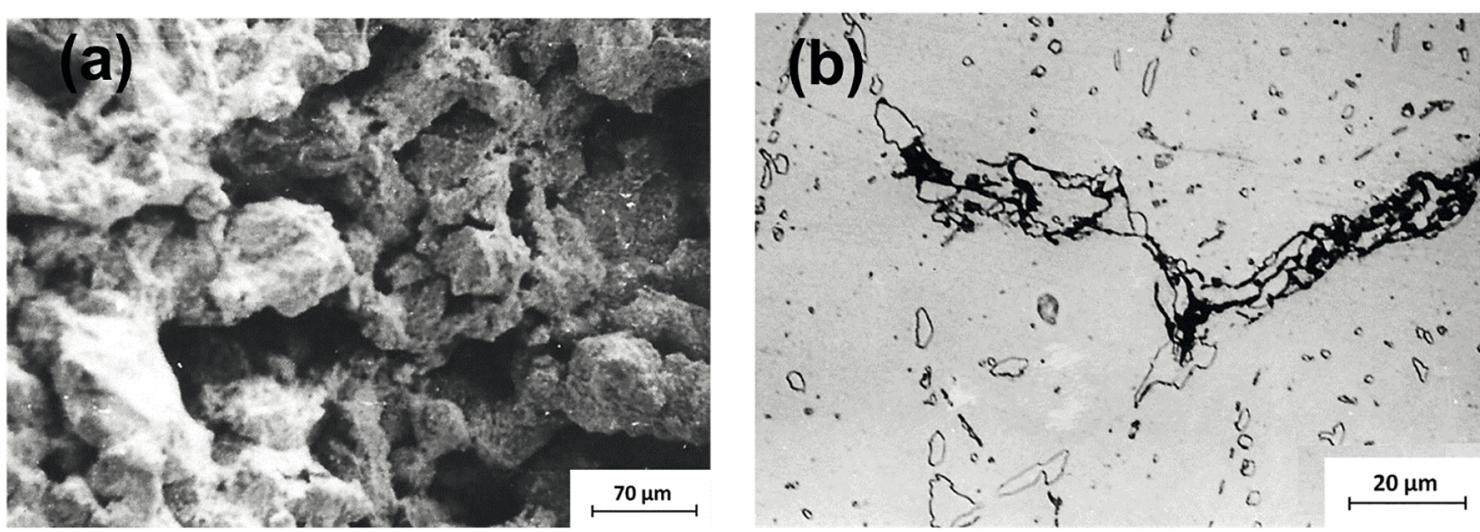

Figure 4. Long time creep fracture for SS1 steel tested at $800^{\circ} \mathrm{C}$ with $\sigma=75 \mathrm{MPa} ; \mathrm{t}_{\mathrm{r}}=95 \mathrm{~h}$; RA $=35 \%$ : (a) SEM and (b) OM.

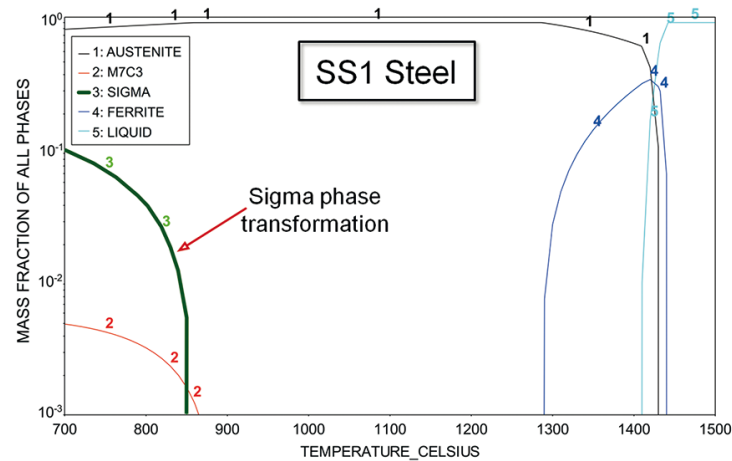

Figure 5. Step cooling Thermo-Calc-based diagram for SS1 steel. The sigma phase transformation curve is indicated by the arrow.

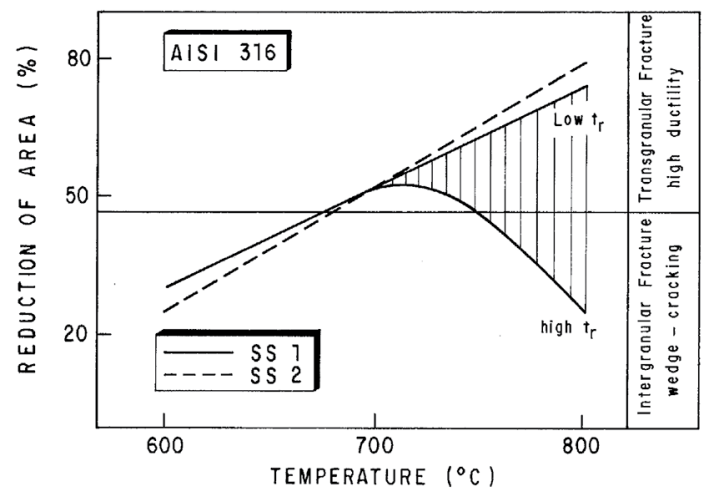

Figure 6. Schematic diagram displaying the creep fracture characteristics of the two investigated 316 steels. 
$T(K)$

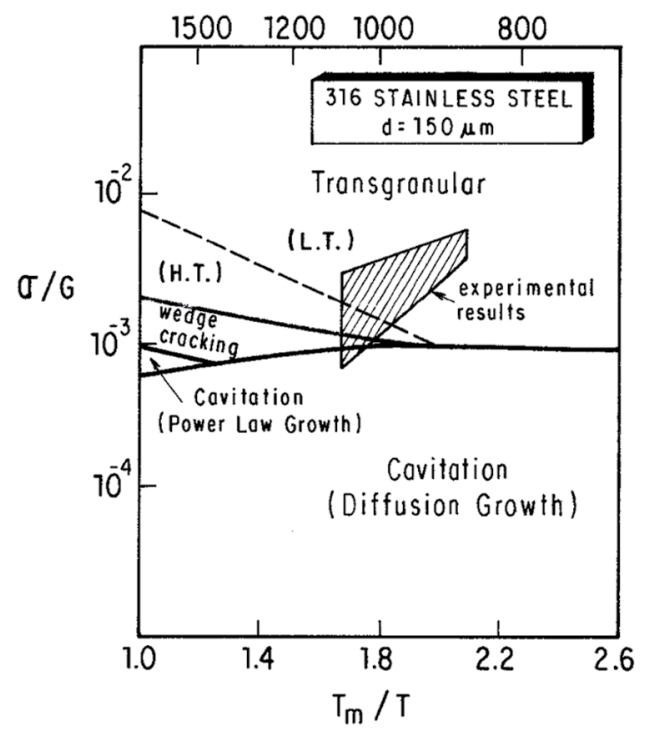

(o)

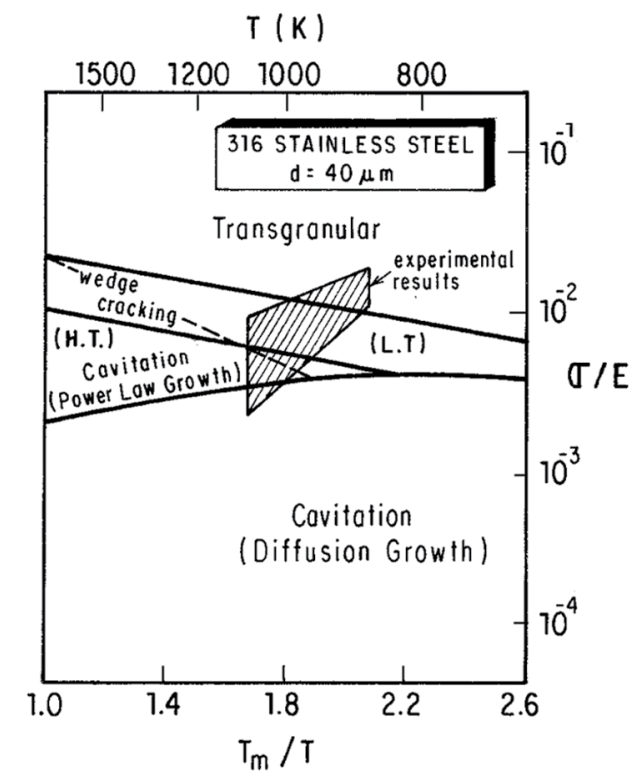

(b)

Figure 7. Model-based fracture maps for AISI type 316 stainless steel with grain sizes of (a) $150 \mu \mathrm{m}$ and (b) $40 \mu \mathrm{m}$ (Adapted from Miller and Langdon ${ }^{8}$ ). Present experimental results are indicated.

ductility transgranular fracture to a low ductility intergranular wedge cracking fracture with decreasing temperature and increasing stress. This kind of transition occurred in both SS1 and SS2 316 steels, as experimentally observed in Fig. 1 to 4 for their creep fracture behavior.

As far as experimental maps are concerned, it may be inferred from Ashby et al. ${ }^{7}$ that FCC metals and alloys should have fracture maps with the same general characteristics. For instance, if one considers the experimental fracture map for nickel ${ }^{7}$ in Fig. 8, a consistency with the present results can be verified. The boundary line between the wedge cracking and ductile transgranular fields in Fig. 6 permits the transitions in fracture characteristics observed in both steels SS1 and SS2, with stress and temperature. One should note that the temperature axis in Fig. 7 is inverted with respect to that in Fig. 8.

The evidences from experimental data both in Ashby et al. ${ }^{7}$ map, Fig. 8 , and in the results shown in the present paper, indicate that the inclination of the boundary line between the fields of transgranular fracture and wedge cracking fracture must be in a way that the stress will vary reversely with the temperature. By contrast, in Miller and Langdon ${ }^{8}$ map, Fig. 7 , this boundary line defines pair of $\sigma$ and $T$ varying in the same direction.

This inconsistency between the experimental $\mathrm{map}^{7}$, Fig. 8, and the model-based map ${ }^{8}$, Fig. 7, can be analyzed in terms of the constitutive equations and the behavior of the fracture mechanisms. The model-based map ${ }^{8}$ was constructed by assuming that the fracture mechanisms operate independently and that failure occurs by the process, which

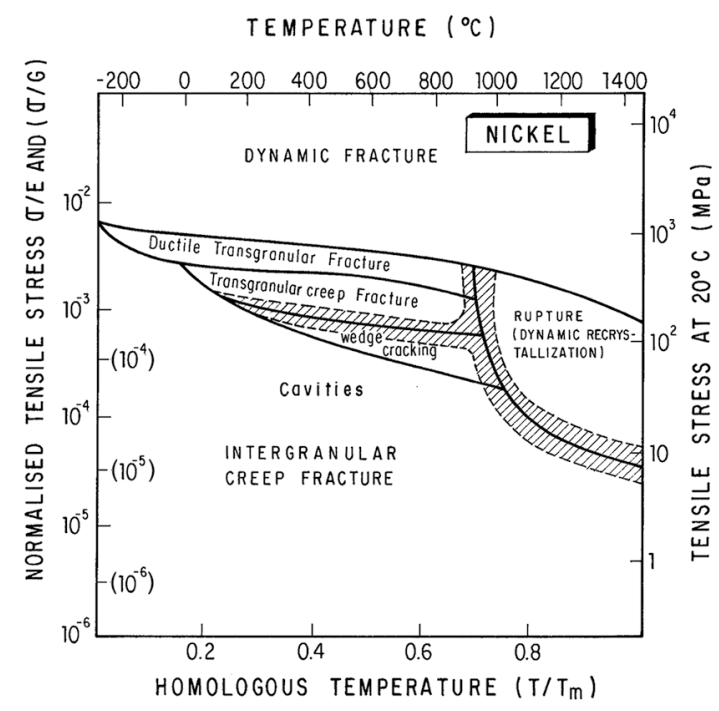

Figure 8. Experimental fracture map of Ashby et al. ${ }^{7}$ for nickel.

leads to the shortest time to fracture $\mathbf{t}_{\mathrm{f}}$. The values of $\mathbf{t}_{\mathrm{f}}$ for transgranular and wedge cracking fracture given by Miller and Langdon ${ }^{8}$ are:

Transgranular:

$$
t_{f}=\left\{\varepsilon_{n}+\left(\frac{1}{i .8}\right)\left(\frac{n}{n-1}\right) \ln \left(\frac{0.7}{f_{v} 1 / 2}-1\right)\right\} \varepsilon^{-1}
$$

Wedge Cracking:

$$
t_{f}=\frac{2 \gamma}{G d \zeta}\left(\frac{\sigma}{G}\right)^{-1} \dot{\varepsilon}^{-1}
$$


where $\sigma$ is the initial tensile stress; $G$ the shear modulus; $\varepsilon_{\mathrm{n}}$ the nucleation strain; $\mathrm{n}$ the coefficient of stress sensitivity; $f_{v}$ the volume fraction of intergranular inclusions; $d$ the grain size; $\zeta$ the contribution of grain boundary sliding to the total strain; and $\dot{\varepsilon}$ the minimum creep rate.

The following constitutive equation for high temperature creep was also considered ${ }^{5,8}$ :

$$
\dot{\varepsilon}=A_{l} D_{0(l)} \exp \left(-Q_{l} / R T\right) \frac{G b}{k T}\left(\frac{\sigma}{G}\right)^{n}
$$

where $\mathrm{A}_{1}$ is a parameter; $\mathrm{D}_{\mathrm{o}(\mathrm{l})}$ the lattice diffusivity, and $\mathrm{Q}_{1}$ the lattice activation energy.

The boundary line between these two creep fracture mechanisms is found by considering equal values for $\mathbf{t}_{\mathbf{f}}$ in both Eq. 1 and 2. It may be seen that if one consider the constant values for $\mathrm{n}, \mathrm{f}_{\mathrm{v}}, \gamma$, assumed by Miller and Langdon ${ }^{8}$, the stress will depend on the temperature only through the shear modulus, G. In this case $\sigma$ will vary in the same way as T. However one should expect that $\mathrm{n}, \mathrm{f}_{\mathrm{v}}$, $\gamma$ and $\zeta$ would also vary with the temperature. Therefore, a reverse dependence between $\sigma$ and $\mathrm{T}$ could well result. Moreover, the assumption that the fracture mechanisms operate independently ${ }^{8}$ is an over simplification. In real situation there will be mixed modes of fracture and the damage introduced by one may influence the operation of others. For instance, cavities may continuously be formed throughout the creep process ${ }^{6,20}$. Boundary sliding leading to cavity nucleation must then be a stochastic process ${ }^{6}$. It is thus conceivable that the formation of wedge cavities may compete with the transgranular mechanisms of fracture and a diffuse transition region might exist rather than the sharp boundaries proposed by Miller and Longdon ${ }^{8}$.

Other factors that may affect the fracture of austenitic stainless steels are the grain boundary precipitation of chromium carbides $\left(\mathrm{Cr}_{23} \mathrm{C}_{6}\right)$, in the interval from 500 to $800^{\circ} \mathrm{C}^{5}$, and the possibility of sigma phase tranformation ${ }^{12-14}$. These are probably reasons for the intergranular fracture observed in steel SS1 at $800^{\circ} \mathrm{C}$. It is supposed that specific conditions related to alloy content and microstructure could make grain boundary precipitation, through the nucleation of cavities at the precipitates ${ }^{21,22}$, the controlling creep fracture mechanism at high temperatures. Diffusion assisted grain boundary precipitation could then be considered an effective creep fracture mechanism in austenitic stainless steels, with a proper field in the fracture maps.

These considerations justify the schematic construction of a model-based map for SS1 316 steel such as the one shown in Fig. 9. Here, a new field corresponding to a creep fracture mechanism controlled by grain boundary precipitation is presented. This is different from the wedge cracking field in Miller and Langdon map ${ }^{8}$, where the crack is formed following grain boundary shear and stress concentration at triple points or inclusions which already exist in the boundary? ${ }^{7}$. Furthermore, in Fig. 9, the dashed lines delimitate a possible region of fracture controlled by DSA. This phenomenon may occur in 316 steel at $600^{\circ} \mathrm{C}^{16}$ $\left(1.9 \mathrm{~T}_{\mathrm{m}} / \mathrm{T}\right)$ and deserves to be indicated in a map owing to its special fracture characteristics.

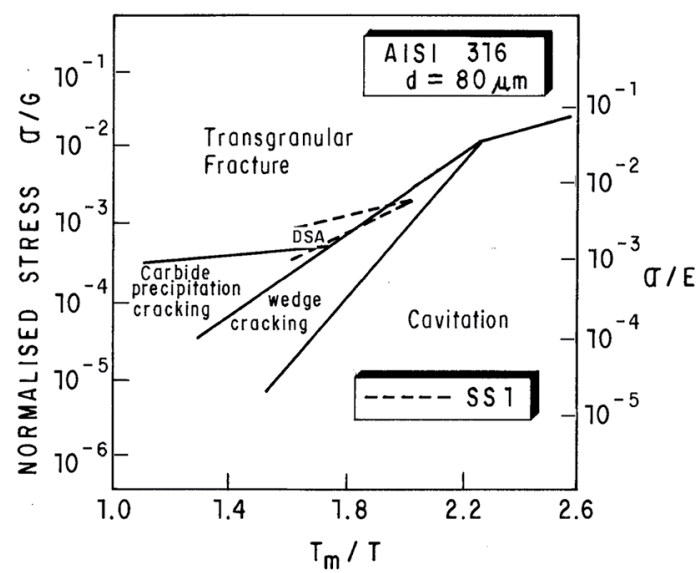

Figure 9. Model-based map for AISI type 316 stainless steel with grain size of $80 \mu \mathrm{m}$.

The field of grain boundary precipitation in Fig. 9 should have constitutive equations similar to that of Eq. 3. Diffusion promotes $\mathrm{Cr}_{23} \mathrm{C}_{6}$ precipitation at the grain boundaries and a power law dependence of the stress assists the nucleation of cavities at the precipitates. Consequently, a linear boundary relationship between $\ln \sigma$ and $1 / T$ should also be expected between this new field and their neighbors' fields of transgranular fracture and wedge cracking.

For SS2 316 steel, which shows only transgranular fracture and high ductility at $800^{\circ} \mathrm{C}$, the corresponding map might be shifted downwards with respect to that of steel SS1 in Fig. 9, possibly without the field corresponding to carbide or sigma phase precipitation cracking. Obviously, like any austenitic stainless steel, $\mathrm{SS} 2$ also undergoes intergranular $\mathrm{Cr}_{23} \mathrm{C}_{6}$ precipitation between 500 and $800^{\circ} \mathrm{C}^{5}$. However, its creep fracture is not apparently controlled by cracking associated with precipitation. Indeed, intergranular fracture is not observed in SS2 steel at $800^{\circ} \mathrm{C}$.

\section{Summary and Conclusions}

- Two distinct austenitic stainless steels of same AISI type 316, one Brazilian SS1 and the other Swedish SS2, were found to present significant differences in creep fracture, especially at $800^{\circ} \mathrm{C}$.

- These differences were identified in fracture mechanism maps of Ashby and collaborators as well as Miller and Langdon, both relating normalized stress and homologous temperature.

- The main creep fracture differences occurred at $800^{\circ} \mathrm{C}$, in which SS1 for long time creep, a relevant 
condition for industrial application, displayed intergranular fracture with wedge cavities and moderate ductility, $\sim 20 \%$, measured by reduction of area (RA).

- $\quad$ On the contrary, $\mathrm{SS} 2$ at $800^{\circ} \mathrm{C}$ for long time creep displayed transgranular fracture with dimple micro-cavities and high ductility, $50-75 \%$ RA.

- The experimental map of Ashby and collaborators was consistent with the present results, while the model-based map of Miller and Langdon required the introduction of other fracture fields related to carbide or sigma phase precipitation and possibly dynamic strain aging.

\section{Acknowledgements}

The authors thank the support to this investigation by the Brazilian agencies: CNPq, CAPES and FAPERJ.

\section{References}

1. Veternikova JS, Degmova J, Pekarcikova M, Simko F, Petriska M, Skarba M, et al. Thermal stability study for candidate stainless steel of GEN IV reactors. Applied Surface Science. 2016;387:965-970.

2. Badhuri AK, Laha K, Ganesan V, Sakthivel T, Nandagopal M, Reddy GVP, et al. Advanced materials for structural components of Indian sodium-cooled fast reactors. International Journal of Pressure Vessels and Piping. 2016;139-140:123-136.

3. Nakae N, Ozawa T, Ohta H, Ogata T, Sekimoto H. An approach for evaluating the integrity of fuel applied in Innovative Nuclear Energy Systems. Journal of Nuclear Materials. 2014;446(1-3):1-9.

4. Parthasarathi NL, Borah U, Albert SK. Effect of temperature on sliding wear of AISI 316 L(N) stainless steel - Analysis of measured wear and surface roughness of wear tracks. Materials \& Design. 2013;51:676-682.

5. Meyers MA, Chawla KK. Mechanical Behavior of Materials. $2^{\text {nd }}$ ed. Cambridge: Cambridge University Press; 2009. p. 653-688.

6. Nix WD, Gibeling JC. In: Raj R, ed. Flow and fracture at elevated temperatures: papers presented at the 1983 ASM Materials Science Seminar, 1-2 October 1983, Philadelphia. Metals Park: ASM; 1985.

7. Ashby MF, Gandhi G, Taplin DMR. Overview No. 3 Fracturemechanism maps and their construction for f.c.c. metals and alloys. Acta Metallurgica. 1979;27(5):699-729.
8. Miller DA, Langdon TG. Creep fracture maps for 316 stainless steel. Metallurgical Transactions A. 1979;10(11):1635-1641.

9. Silveira TL, Monteiro SN. Creep fracture behavior of austenitic stainless steel from 550 to $800^{\circ} \mathrm{C}$. In: Proceedings of the $5^{\text {th }}$ International Creep Fracture; 1981 Mar 29-Apr 3; Cannes, France. p. 1595-1601.

10. White WE, Le May I. Microstructural Analysis of Two AISI Type 316 Stainless Steels. Microstructural Science. 1974;2:4962.

11. Weiss B, Stickler R. Phase instabilities during high temperature exposure of 316 austenitic stainless steel. Metallurgical and Material Transactions B. 1972;3(4):851-866.

12. Senior BA. Effect of phase transformation on the creep rupture properties of two type 316 weld metals. Journal of Materials Science. 1990;25(1):45-53.

13. Villanueva DME, Pimenta FC Jr., Plaut RL, Padilha AF. Comparative study on sigma phase precipitation on three types of stainless steels: austenitic, superferritic and duplex. Materials Science and Technology. 2006;22(9):1098-1104.

14. Hsieh CC, Wu W. Overview of Intermetallic Sigma $(\sigma)$ Phase Precipitation in Stainless Steels. ISRN Mettalurgy. 2012;2012:732471. DOI: 10.5402/2012/732471

15. Pimenta FC Jr., Padilha AF, Plaut RL. Sigma Phase Precipitation in Superferritic Stainless Steel. Materials Science Forum. 2003;426-432:1319-1324.

16. Christopher J, Chodhary BK. On the assessment of tensile work hardening behaviour of type $316 \mathrm{~L}(\mathrm{~N})$ austenitic stainless steel in the framework of $\theta \sigma \mathrm{d}$ vs. $\sigma \mathrm{d}$ using flow stress contribution from dislocations. International Journal of Pressure Vessels and Piping. 2016;146:151-160.

17. ASTM International. ASTM E8/E8M-15a-Standard Methods for Tension Testing of Metallic Materials. West Conshohocken: ASTM International; 2015.

18. Monteiro SN, Margem FM, Braga FO, Louro LHL. Fracture behavior of 316 stainless steel under creep at 600 and $800^{\circ} \mathrm{C}$. Materials Science Forum. 2016;869:520-526.

19. Hattersley B, Hume-Rothery W. Constitution of certain austenitic steels. Journal of the Iron and Steel Institute. 1966;204:683-701.

20. Dyson BF. Continuous cavity nucleation and creep fracture. Scripta Metallurgica. 1983;17(1):31-37.

21. Beere W. Models of creep cavitation and their interrelationships. Scripta Metallurgica. 1983;17(1):13-16.

22. Goods SH, Nieh TG. Mechanisms of intergranular cavity nucleation and growth during creep. Scripta Metallurgica. 1983;17(1):23-30. 